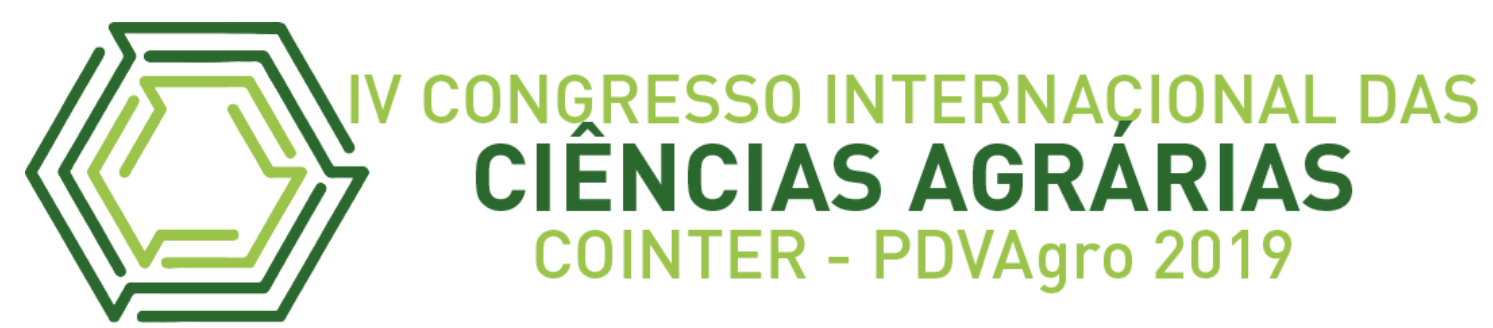

\title{
IMPACTOS SOCIAIS E AMBIENTAIS DO CULTIVO DE DENDEZEIRO NO ESTADO DO PARÁ
}

\author{
IMPACTOS SOCIALES Y AMBIENTALES DE LA CULTURA DE DENDEZEIRO \\ EN EL ESTADO DE PARÁ
}

\author{
SOCIAL AND ENVIRONMENTAL IMPACTS OF GROUND \\ CULTIVATION IN THE STATE OF PARÁ \\ Apresentação: Comunicação Oral
}

Mateus Higo Daves Alves ${ }^{1}$; Matheus Henrique Resueno dos Santos²; Markus Wybero Nunes Brito ${ }^{3}$; Ruy Geovane Monteiro de Souza ${ }^{4}$; Dioclea Almeida Seabra Silva ${ }^{5}$.

\section{DOI: https://doi.org/10.31692/2526-7701.IVCOINTERPDVAgro.2019.0095}

\section{RESUMO}

Este artigo tem por objetivo colocar em pauta, através de levantamento bibliográfico, os principais problemas socioambientais ocasionados com o estabelecimento de grandes áreas ocupadas pelo cultivo de dendezeiro nos municípios do estado do Pará. Do ponto de vista Agronômico, as vantagens econômicas e produtivas do dendê (Elaeis guineensis) comparadas as outras palmas e oleaginosas, são indiscutíveis, no entanto, as grandes extensões de terras necessárias para sua implantação bem como a quantidade elevada de maquinários e insumos químicos vem ocasionando constantes impactos sociais $\mathrm{e}$ ambientais para ribeirinhos, quilombolas, indígenas e agricultores familiares próximos a esta monocultura, ocasionando mudanças nos aspectos territoriais, sociais e na qualidade de vida dos mesmos. As empresas de palma absorvem grande quantidade de mão de obra local, além de realizar programas de incentivo de implantação da cultura na agricultura familiar, o que reduz a pluralidade de culturas de subsistência e culturais implantadas e comercializadas na região. Com base na pesquisa realizada, pode-se afirmar que mesmo tendo um potencial econômico indiscutível, alavancando o PIB do estado no segmento agrícola e gerando emprego e renda a diversas famílias e trabalhadores rurais (Rural Palmar), a dendeicultura ainda pouco demonstra ser social e ambientalmente sustentável, ademais neste momento a qual tanto se prega a sustentabilidade, tendo em vista o quanto de impactos ambientais se observa no uso indiscriminado de agrotóxicos na cultura, que por consequência vem causando danos aos recursos hídricos, inviabilizando o uso da água pela comunidade local, ocasionado diversos problemas respiratórios e dermatológicos, além de reduzir a biodiversidade na região.

Palavras-chave: dendê, impacto socioambiental, famílias rurais.

\section{RESUMEN}

El propósito de este artículo es presentar, a través de una encuesta bibliográfica, los principales problemas sociales y ambientales causados por el establecimiento de grandes áreas ocupadas por el cultivo de palma aceitera en los municipios del estado de Pará.

\footnotetext{
${ }^{1}$ Bacharelado em Agronomia, UFRA Campus Capanema, PA. mateushigo.alves@gmail.com ${ }^{2}$ Bacharelado em Agronomia, UFRA Campus Capanema, PA, matheusresueno@ hotmail.com.

${ }^{3}$ Bacharelado em Agronomia, UFRA Campus Capanema, PA, markus.wybero22@gmail.com
} 


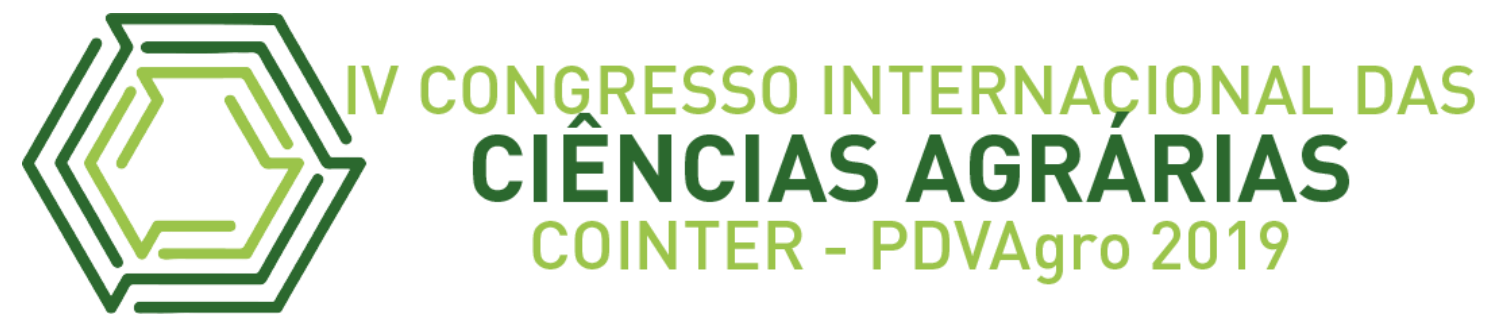

\begin{abstract}
${ }^{4}$ Bacharelado em Agronomia, UFRA Campus Capanema, PA, Geovane.loudg1@ gmail.com ${ }^{5}$ Doutorado, UFRA Campus Capanema, PA, diocleaseabra85@gmail.com
\end{abstract}

Desde el punto de vista agronómico, las ventajas económicas y productivas de la palma aceitera. (Elaeis guineensis) en comparación con otras palmeras y semillas oleaginosas, son indiscutibles, sin embargo, las grandes extensiones de tierra requeridas para su implementación, así como la gran cantidad de maquinaria e insumos químicos han causado constantes impactos sociales y ambientales para los ribereños, quilombolas, indígenas y Agricultores familiares cercanos a este monocultivo, que provocan cambios en su calidad de vida territorial, social y. Las empresas de palma absorben una gran cantidad de mano de obra local, así como también llevan a cabo programas de incentivos para la implantación de la cultura en la agricultura familiar, lo que reduce la pluralidad de cultivos de subsistencia y culturales implantados y comercializados en la región. Con base en la investigación, se puede afirmar que, incluso teniendo un potencial económico indudable, aprovechando el PIB del estado en el segmento agrícola y generando empleo e ingresos para varias familias y trabajadores rurales (Rural Palmar), el aceite de palma todavía muestra poca actividad social y económica. ambientalmente sostenible, además, en este momento, que predica tanta sostenibilidad, considerando la cantidad de impactos ambientales que se observan en el uso indiscriminado de pesticidas en el cultivo, lo que en consecuencia ha estado causando daños a los recursos hídricos, lo que hace que el uso del agua por parte de la comunidad local sea inviable. , causando varios problemas respiratorios y dermatológicos, además de reducir la biodiversidad en la región.

Palabras clave: aceite de palma, impacto socioambiental, familias rurales.

\title{
ABSTRACT
}

he purpose of this article is to present, through a bibliographic survey, the main social and environmental problems caused by the establishment of large areas occupied by oil palm cultivation in the municipalities of the state of Pará. From the agronomic point of view, the economic and productive advantages of oil palm. (Elaeis guineensis) compared to other palms and oilseeds, are undisputed, however, the large extensions of land required for its implementation as well as the high amount of machinery and chemical inputs has caused constant social and environmental impacts for riparian, quilombola, indigenous and family farmers close to this monoculture, causing changes in their territorial, social and quality of life. Palm companies absorb a large amount of local labor, as well as carry out incentive programs for the implantation of culture in family agriculture, which reduces the plurality of subsistence and cultural crops implanted and marketed in the region. Based on the research, it can be stated that even having undoubted economic potential, leveraging the state's GDP in the agricultural segment and generating employment and income for several families and rural workers (Rural Palmar), palm oil still shows little social and environmentally sustainable, in addition at this time which preaches so much sustainability, considering how much environmental impacts are observed in the indiscriminate use of pesticides in the crop, which consequently has been causing damage to water resources, making the use of water by the local community unfeasible. , causing several respiratory and dermatological problems, besides reducing the biodiversity in the region.

Keywords: palm oil, socioenvironmental impact, rural families. 


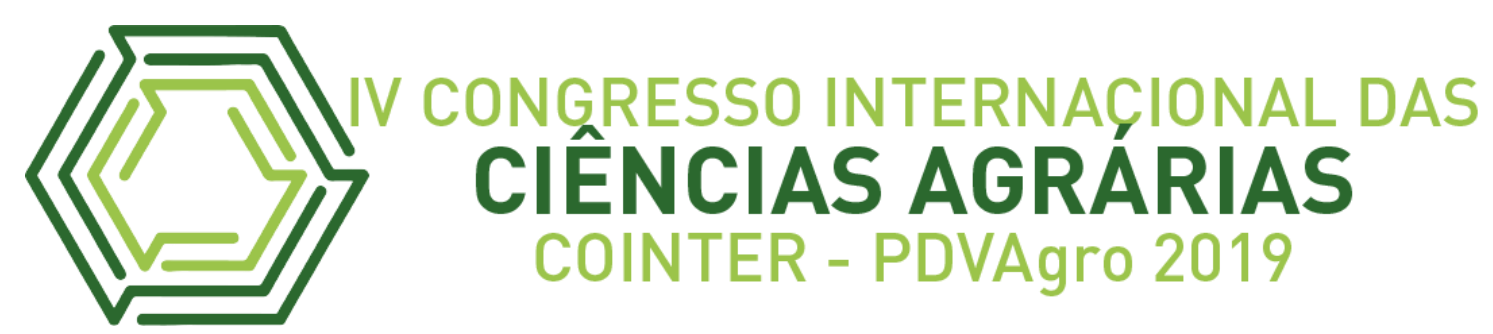

\section{INTRODUÇÃO}

O dendezeiro (Elaeis guineenses), é uma espécie de palmeira bastante cultivada no Brasil, esta teve como centro de origem o continente africano e o destaque dar-se devido a elevada produção de óleo até mesmo em pequenas unidades de área. No Brasil, dentre os óleos vegetais empregados na produção de biodiesel, o dendê se destaca aos demais, sendo uma opção ao diesel de petróleo e contribuindo para a geração de um mercado para a produção em grande escala de biodiesel (BRAZILIO et al. 2012).

De acordo com Veiga et al (2009), no Pará, a ascensão do dendê teve início por volta de 1967 apoiado pela Superintendência do Desenvolvimento da Amazônia (SUDAM), que neste período, iniciou o projeto com a implantação de $1.500 \mathrm{~h}$ de dendê estabelecidos no município de Benevides, Nordeste do Pará, pelo convênio firmado com o Institut de Recherches pour les Huiles et Oléagineux (IRHO - França), posteriormente houve privatização do projeto, dando origem à empresa pioneira do setor, Dendê do Pará S.A. - DENPASA.

Em 1980 conforme Santo, Valois e Neto (1984), foi criado o programa Nacional de Pesquisa de Dendê - PNP Dendê da EMBRAPA, com o objetivo de dar suporte tecnológico ao desenvolvimento da cultura do dendezeiro no Brasil, a qual atuava sob a coordenação do Centro Nacional de Pesquisa de Seringueira e Dendê.

Em 1982, no município de Tailândia, no estado do Pará se estabelece a empresa de palma denominada Companhia Real Agroindustrial S.A (CRAI), que posteriormente se tornaria AGROPALMA S/A, que até outubro de 2018 possuía 39 mil hectares de palmeiras já plantadas (AGROPALMA, 2018).

Entre os anos de 2003 e 2004, a dendeicultura se expande significativamente e consigo, cresce a produção de óleo principalmente para a produção de biocombustível. Com isso, muitas outras empresas viram uma oportunidade econômica mais que viável neste segmento agrícola levando assim, os surgimentos de diversas outras empresas como a BIOPALMA S/A que atualmente possui quatro polos de produção na região do vale do Acará e baixo Tocantins no Pará. com cerca de 56 mil hectares de palma 


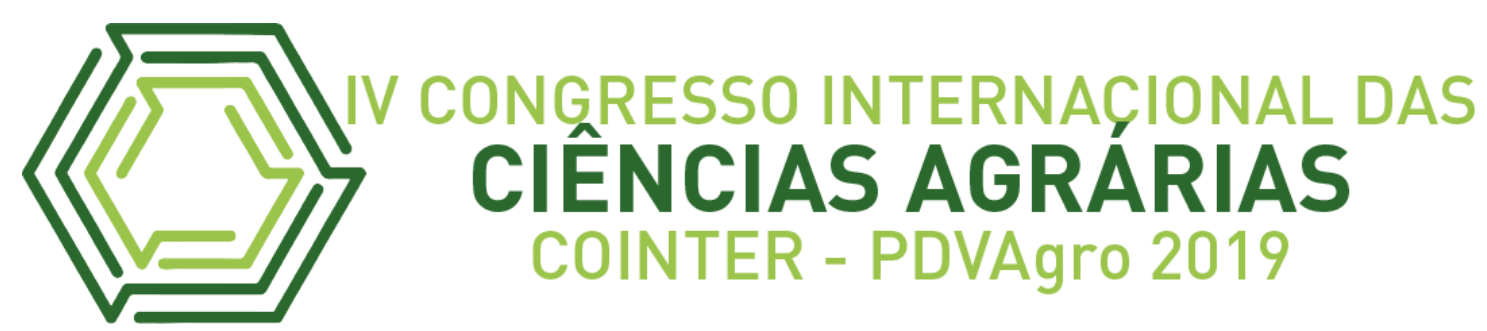

de óleo plantadas em terras próprias, e 6,8 mil hectares em parceria com Agricultura Familiar (BIOPALMA, 2019).

Além das empresas aqui citadas, diversas outras empresas de mesma importância se situam no Pará (Figura 1), onde de acordo com Nahum e Santos (2013), às políticas estatais associadas aos interesses empresariais criam condições e possibilidades para formar territórios-rede do dendê, os quais se distribuem predominantemente pela macrorregião do nordeste paraense, singularizando-se pela descontinuidade, configurando-se como territórios-rede (HAESBAERT, 2004)

Figura 1 - Empresas de dendeicultura no estado do Pará até o ano de 2015.

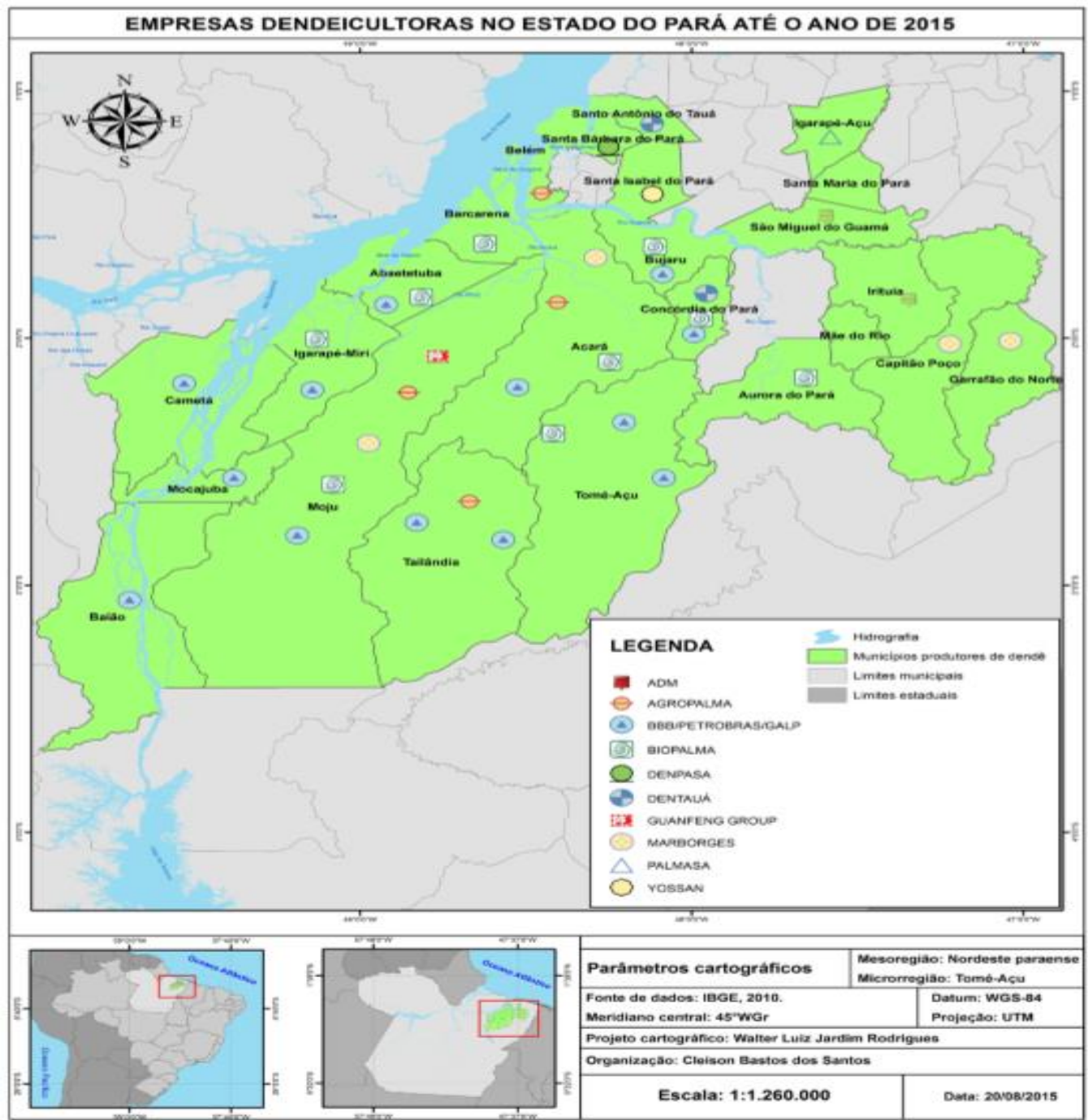

FONTE: Nahum e Santos, 2016. 


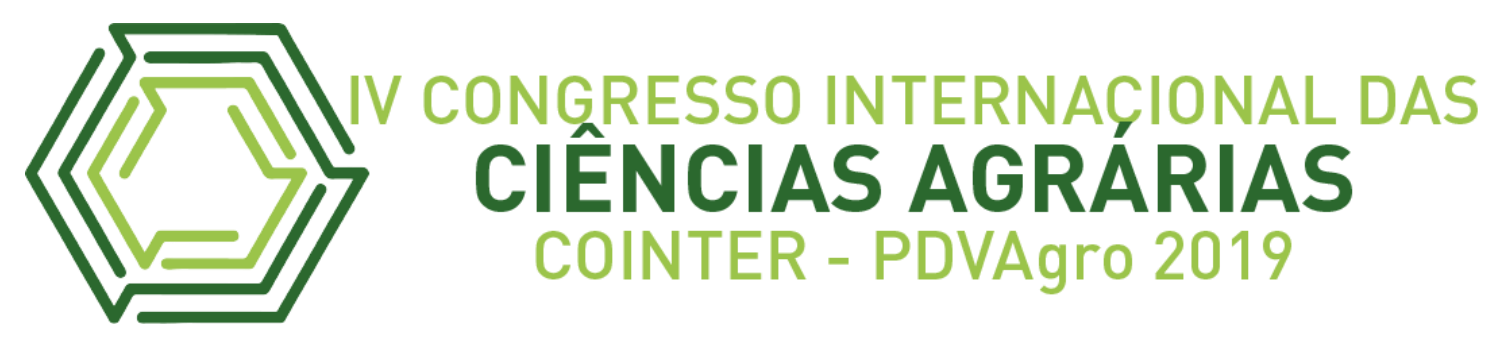

Müller (2005), mostra em seus estudos que atualmente distinguem-se dois grandes pólos de desenvolvimento da dendeicultura no Estado do Pará. O primeiro deles abrange os seguintes dos municípios de Tailândia, Mojú e Acará, situados ao sul de Belém, o segundo, corresponde aos Municípios de Benevides, Santa Izabel do Pará, Santo Antônio do Tauá, Castanhal, Igarapé-Açu, localizados à nordeste da capital paraense.

Um dos principais fatores para o Nordeste Paraense estar associado a cultura do dendê é o clima da região, fazendo com que a cultura se desenvolva em pleno vigor, visto que a região se caracteriza por dois períodos sazonais distintos: chuvoso e menos chuvoso. O período chuvoso apresenta índices pluviométricos suficientes para favorecer o crescimento acelerado na implantação de novas áreas de cultivo de dendê.

Baseado neste contexto, este trabalho tem como objetivo explanar sobre os impactos socioambientais da dendeicultura no estado do Pará, em especial, aos agricultores familiares, a partir de revisão de literatura de autores, que estudam a cultura do dendê na região.

\section{IMPACTOS SOCIOAMBIENTAIS DA CULTURA DO DENDÊ}

A seguir serão expostos alguns impactos socioambientais da dendeicultura. Ressalta-se que há tanto impactos positivos como negativos, conforme serão descritos.

De acordo com Brito (s/d), não há atividade econômica no mundo que realizada pelo ser humano não cause algum tipo de impacto sócio-ambiental, entretanto, a cultura da palma consiste em uma das mais criticadas no mundo.

De acordo com Brasilio et al. (2012), no Brasil, dentre os óleos vegetais empregados na produção de biodiesel, o dendê se destaca aos demais, sendo uma opção ao diesel de petróleo e contribuindo para a geração de um mercado para a produção em grande escala de biodiesel. Da mesma forma, Brito (s/d), afirma que por suas características, a cultura da palma apresenta excelente desempenho como atividade âncora em programas de interiorização e fixação do homem ao campo, nos projetos de colonização, e reforma agrária, cooperativas e outros modelos de assentamento rural.

Segundo Nahum e Malcher (2010) os pensamentos apontados pelo Zoneamento Agroecológico do Dendezeiro referentes às zonas Desmatadas da Amazônia Legal, 


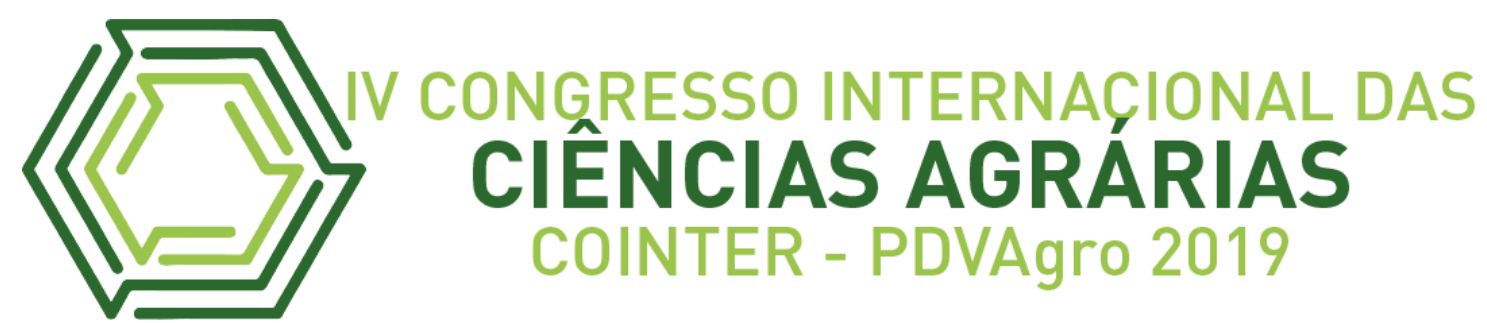

elaborado pela Embrapa, Centro Nacional de Pesquisas de Solos e pelo Ministério da Agricultura, Pecuária e Abastecimento corroboram o crescimento acelerado da dendeicultura. Este trabalho possibilitou a identificação das áreas mais propícias à expansão sustentável do cultivo de dendê. "O somatório das áreas identificadas corresponde a 31,8 milhões de hectares" (VENTURIERI, 2011, p. 16).

Segundo Pandolfo (1978), o custo agrícola de grandes plantações, envolvendo os recursos necessários para implantação e manutenção, até o início da produção, é de US\$ 2,800.00 por hectare.Além de ocupar uma posição de destaque na produção de matériaprima para a geração de energia renovável de origem agrícola somando-se a matriz energética brasileira e como alternativa aos combustíveis fósseis, o país dispõe de extensas áreas agricultáveis que podem ser incorporadas ao processo produtivo de maneira sustentável (BRAZILIO et al. 2012). Podemos dizer a partir disso então que o cultivo de dendezeiro impacta positivamente a sociedade neste sentido, visando a geração de renda e emprego não apenas devido a grandes empresas que cultivam esta palma, mas também a pequenos agricultores que tem como subsistência o plantio da espécie.

De acordo com a Secretaria de Agricultura do Estado do Pará (2005) a produção no estado com o dendê corresponde a um percentual de cerca de 747.666 ton/ano/óleo. Esse valor produtivo significa uma participação considerável na arrecadação de receitas para o Estado, de acordo com dados da mesma secretaria, cerca de 50\% da média do PIB agropecuário do Pará está se concentra no vale dos rios Acará e Moju, área que correspondem, a parte das empresas processadoras de dendê.

Além do aumento de consumo decorrente do crescimento populacional e da elevação do poder aquisitivo da população, verifica-se que os óleos vegetais ganham a preferência de consumo, em comparação às gorduras de origem animal, devido causarem menos problemas para a saúde humana. (MÜLLER \& ALVES, 1997).

Além dos aspectos econômicos já mencionados, Furlan Júnior et al (2006), frizam que o cultivo da palma é capaz de promover o desenvolvimento sustentável, uma vez que, recuperaria ambientalmente, economicamente e socialmente áreas degradadas pela pecuária. Já Nahum e Bastos (2014) afirmam que o cultivo do dendê constitui um evento, pois reorganiza a paisagem, a configuração territorial, a dinâmica social, enfim o espaço geográfico ou território usado, neste último caso, concordando com Jurlan Junior. 


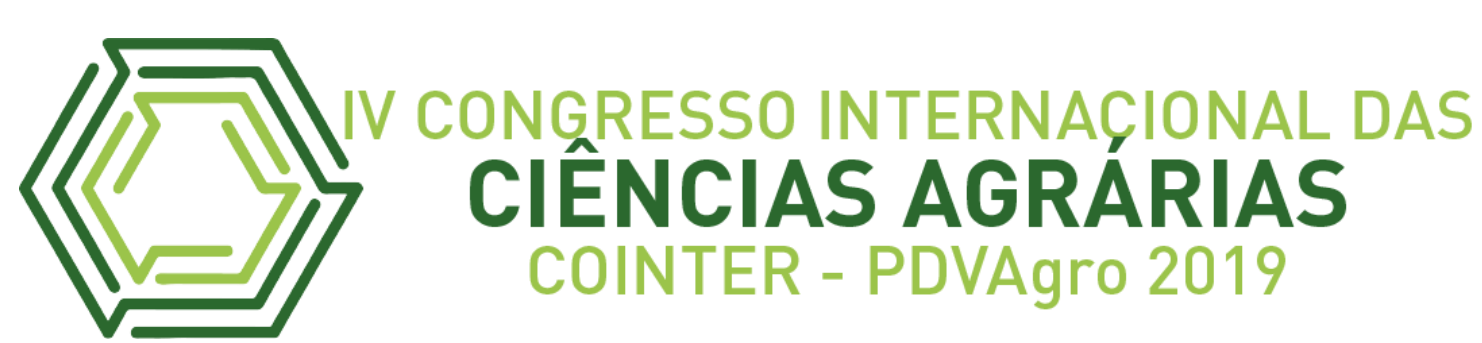

No contexto ambiental, infelizmente o impacto no cultivo do dendezeiro traz algumas consequências negativas: hoje a diversidade das florestas tropicais do mundo como um todo, vem diminuindo de maneira alarmante. Atualmente, estima-se que foram substituídos 27 milhões de hectares de florestas virgens por uma única espécie de árvore, o monocultivo de dendê.

Um dos principais impactos ambientais do dendê já detectados no nordeste paraense (depois da onda de desmatamentos praticados por - ou a mando de - empresas em lotes de agricultura familiar para a implantação de dendê, entre 2008 e 2010) tem sido a contaminação por agrotóxicos de igarapés que alimentam os inúmeros rios - como o Pará, Tocantins, Moju, Acará, Acará-Mirim, Capim, Auiaçu, Maracanã e Camari, entre outros da região (REPÓRTER BRASIL, 2013).

Segundo Cruz e Farias (2017), O uso do agrotóxico, como forma de controle de pragas e doenças e como garantia de produtividade, põe em risco o ecossistema terrestre e aquático, pois a forma de uso que o Brasil vem aplicando e definindo em suas políticas públicas faz com que ocorram inúmeros problemas de contaminações nos ecossistemas, colocando em sérios riscos os meios bióticos e abióticos, devido aos efeitos deletérios dos ditos agrotóxicos.

A gama de produtos fitossanitários utilizados para controle de ervas invasoras é bem extensa, fato este que preocupa ainda mais devido, a diversidade de princípios ativos, conforme são discriminados no Quadro 1, que acabam acarretando em contaminações ambientais.

Quadro 1: Principais agrotóxicos utilizados na dendeicultura.

PRODUTO INGREDIENTE ATIVO

Roundup líquido e pó

Connect líquido

Turbo líquido

Provado 200 SC

Evidence $700 \mathrm{WG}$
Equivalente de N- (fosfometil) glicinaGlifosato, glifosatoSal de Isopropilamina Beta - Ciflutrina, Imidacloprido

Beta- ciflutrina

Imidacloprido

Imidacloprido 


Hidróxido de cobre (Ellect)
Alquilenobis (ditiocarbamato)
Dittany em pó
DA 806 BR
Tordon
2,4-D dimetilamina
Trisopropanolamina, Amino Piralide Engeo pleno
Lominum
Zartan
Aminopiralide, Fluroxipir-Meptilico
ptilico Zartan Matsulfurom-metilico

Fonte: Adaptada de Cruz e Farias, 2017.

Do ponto de vista social, Cruz e Farias (2017), alerta que a implantação da dendeicultura provoca um processo de descampesinização, isto é, um campo sem camponeses, paulatinamente impulsionado pela ausência de políticas de Estado para o campo, sobretudo para as comunidades rurais camponesas e como consequência, redireciona a classe camponesa para reprodução de um modo de vida que não é o seu.

Dentre outros fatores, o avanço da dendeicultura nos municípios paraenses acaba por alterar os aspectos da agricultura familiar, como a maximização o êxodo rural, diminuição das práticas agrícolas tradicionais e a redução de áreas destinadas a mesma.

De acordo Siqueira (2018), problemas antigos, que haviam diminuído voltaram, como é o caso da concentração de terras, algo que vem acontecem devido a necessidade áreas para a cultura do dendê, que usa a velha fórmula do latifúndio. Questões ambientais também fazem parte da agenda de debates sobre a cultura. O desvio da função primordial do produtor familiar que antes produzia alimentos e hoje planta a palmeira do dendê, deve ser visto como um problema, uma vez que os coloca em risco, a segurança alimentar dos agricultores familiares.

Onde de acordo com Nahum e Vieira (2013), o fato de agricultores da comunidade trabalharem na cultura do dendê impactou a produção e o preço do principal ingrediente da dieta alimentar do caboclo, a farinha.

Homma e Vieira (2012), afirmam que a alta nos preços da farinha de mandioca no estado tem sido causada, em parte, pela substituição de áreas produtoras de mandioca por 


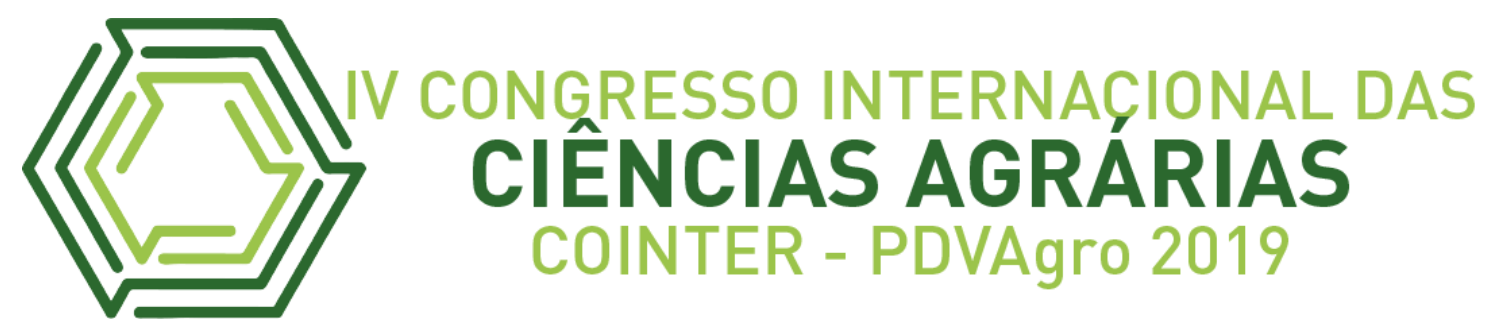

dendezais em municípios do estado do Pará. A figura 2 ilustra a relação entre a dinâmica da dendeicultura nos territórios onde ela aporta e a produção de mandioca. O gráfico mostra claramente que a quantidade da mandioca aumenta ou reduz com a cultura do dendê.

Figura 2 - Produção de mandioca e dendê em Moju no período de 1991 a 2011.

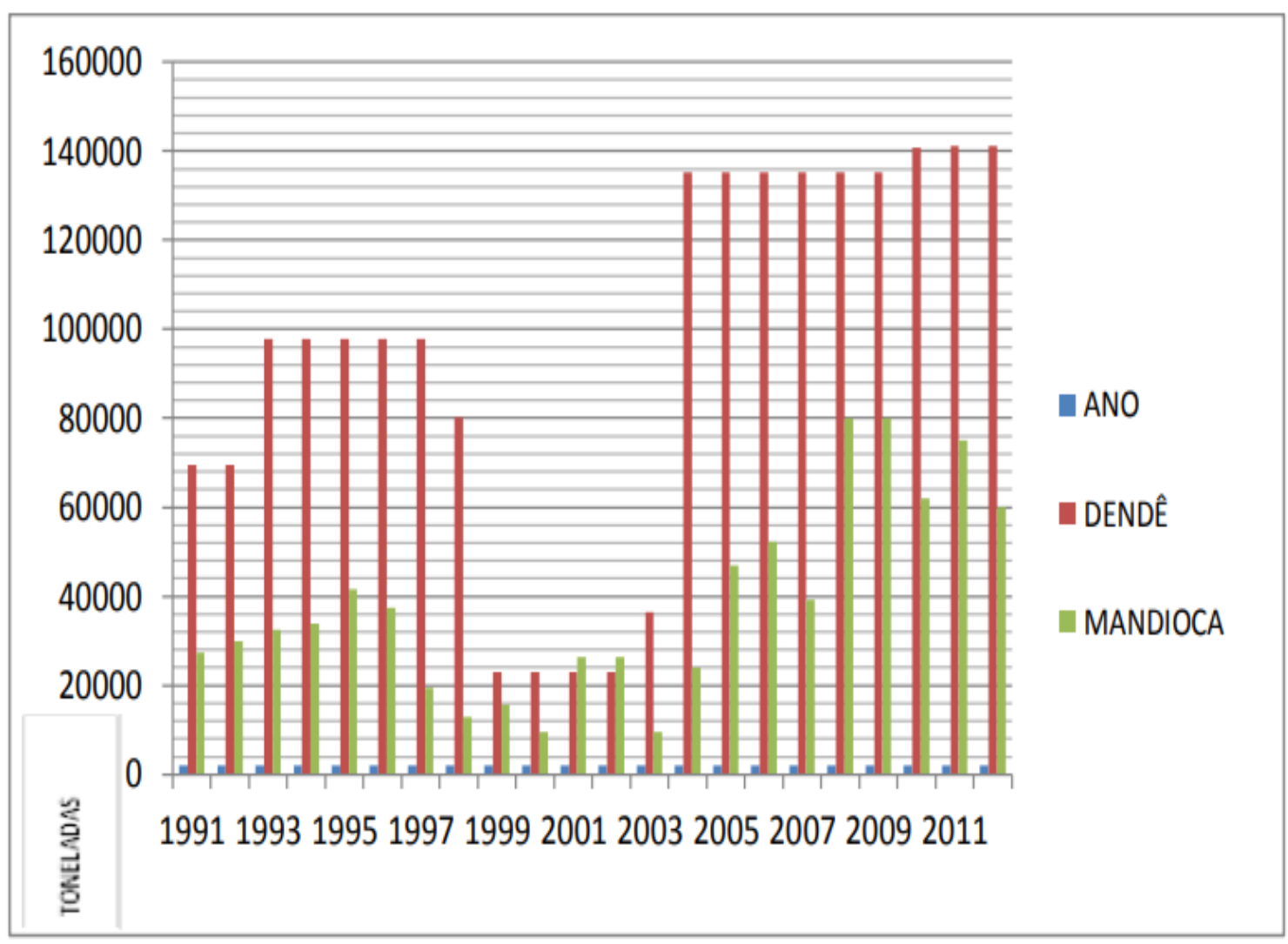

FONTE: IBGE (2010).

Em relação a situação socioeconômica dos agricultores familiares paraenses, pode se dizer que grande parte tem renda mensal de menos de 1/2 salário mínimo, e grande parte tem como forma de subsistência o cultivo de espécies como mandioca e milho, além da criação de animais de pequeno porte. Diante disso, a incorporação de projetos de cultivo de dendê no estado do Pará tem grande influência sendo dada como uma atividade de extrema significância para geração de renda e emprego para a agricultura familiar.

De acordo com Silva (2017), a dendeicultura foi implantada nos estabelecimentos familiares no Nordeste Paraense porque se conformou um contexto favorável à expansão 


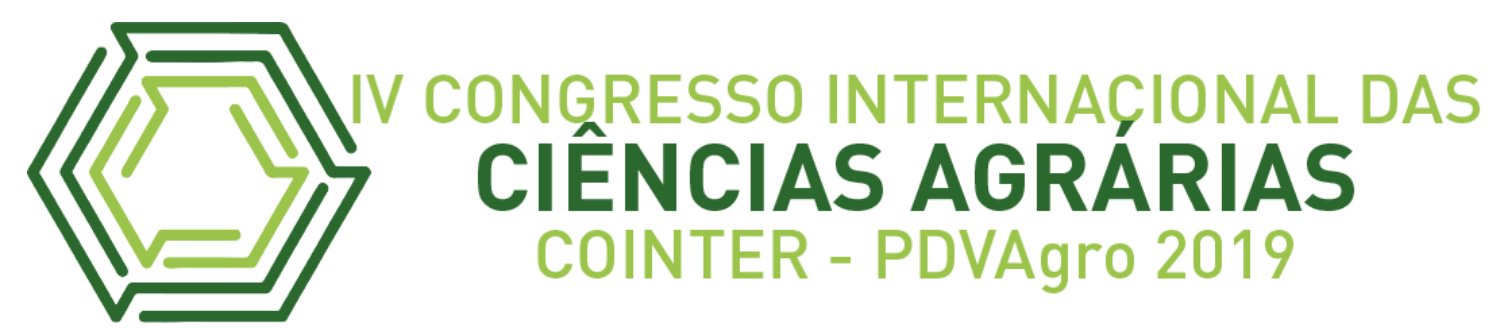

do dendê, determinado por fatores internos e externos. Além da renda gerada às famílias paraenses devido a empregos gerados pelas grandes empresas dendeicultoras, tem-se também o aumento do cultivo em pequena escala nas próprias áreas agricultáveis dos agricultores familiares, onde, tendo por base os dados do Banco da Amazônia S/A, de 2010, observa-se que até maio de 2016 foram celebrados 1.137 contratos de projeto da Agricultura Familiar com Cultura de Dendê, nos municípios de Acará, Aurora do Pará, Baião, Bujaru, Cametá, Castanhal, Concórdia do Pará, Capitão Poço, Garrafão do Norte, Igarapé-açu, Irituia, Mãe do rio, Mocajuba, Moju, São Domingos do Capim, Tailândia e Tomé-açu.

Entende-se aqui como agricultura familiar uma categoria genérica que engloba uma diversidade de formas de organização social da produção que tem como características principais a centralidade da família nas decisões e organização do estabelecimento agrícola e na construção do patrimônio familiar, como explica Wanderley (2009). Os agricultores familiares, desenvolvem sistemas de produção bem diversificados, combinando cultivo de espécies temporárias e permanentes, sendo a dendeicultura inserida nesse contexto.

Diante de todas problemáticas exposta, o grande desafio das grandes empresas é como se desenvolver sustentavelmente e ao mesmo tempo, buscar mitigar os efeitos indesejáveis desse desenvolvimento. A Partir desta indagação, as duas principais empresas de extração de óleo de palma situadas na amazônia (Biopalma S/A e Agropalma S/A) utilizam-se de programas socioeconômicos e de sustentabilidade.

De acordo com Agropalma (2019), a empresa sabe a importância do seu papel na sociedade e na comunidade em que está inserida. Por isso, a empresa promove ações socioeconômicas que visam melhorar a qualidade de vida das pessoas que moram na região Amazônica.Por meio de parcerias com diversas entidades governamentais, promove atividades que contribuem para a geração de renda e emprego.

Desta forma, a empresa afirma que tem como princípios norteadores das suas atividades o respeito ao meio ambiente e o desenvolvimento sustentável, sendo que cada vez mais, práticas sustentáveis assumem papel importante no dia a dia da organização e ajudam a reduzir drasticamente o impacto ambiental, desta forma, a cada hectare de plantação de palma, a Agropalma se compromete a conservar 1,6 hectare de floresta, promovendo ações para conhecer, proteger e preservar a fauna e a flora da região. 


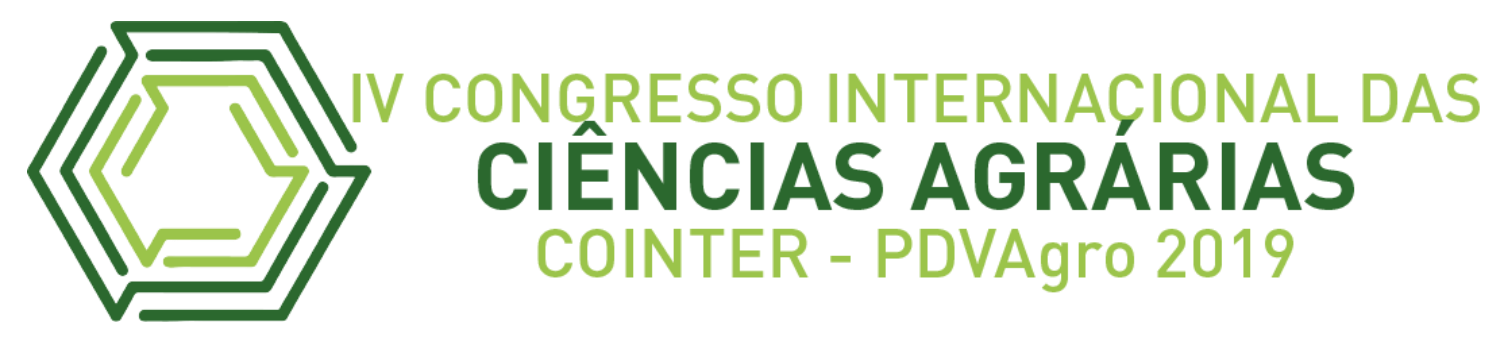

De acordo com a Biopalma S/A (2016), a empresa apresenta um relatório de Sustentabilidade anualmente, a qual exibe a adoção de práticas sustentáveis na cadeia de produção da palma realizadas pela empresa, a qual busca o equilíbrio entre crescimento econômico, desenvolvimento social e proteção ambiental. A mesma possui cerca de 157 mil hectares de terras das quais aproximadamente 95 mil hectares são ocupados por reservas florestais protegidas e áreas de preservação permanentes, sendo e 88.907 hectares de florestas aptas para reserva legal, e cerca de 4.555 hectares identificados como Áreas de Preservação Permanente (APPs) onde não se permite supressão vegetal, pesca e caça, o que viabiliza a sequência dos regimes ecológicos no interior dessas áreas.

Em relação à responsabilidade social, a Biopalma S/A (2016), afirma que o território no qual a empresa realiza suas atividades são composto por 10 municípios do nordeste Paraense, abrangendo 7,78\% da população total do Pará, 4,87\% da população urbana do Pará e 14,09\% população rural do Pará, a qual a produção originária de suas atividades contribui para que o percentual do PIB deste território represente 1,3\% do PIB do Estado do Pará. Dentro deste panorama, a Biopalma constitui-se como um significativo agente de transformação do território, na medida em que mobiliza recursos humanos e materiais capazes de proporcionar alterações que passam tanto pela produção de riqueza quanto pela dinâmica populacional e o padrão de uso dos recursos da natureza.

\section{CONSIDERAÇÕES FINAIS}

Com base na análise da dendeicultura no estado Pará mais especificamente no Nordeste Paraense a partir de revisão de literatura é possível afirmar que essa atividade agrícola tem importância do ponto de vista socioeconômico, ao alavancar a PIB do estado no segmento agrícola, ao mesmo tempo em que gera trabalho e renda na região, tanto nas áreas de cultivos e unidades agroindustriais das empresas do ramo como para as famílias da agricultura familiar, que aderiram ao cultivo de dendê em suas terras, com a elevação de renda.

Por outro lado, o avanço de cultivo provoca a concentração de terra e como consequência tem o êxodo rural na região. Quanto aos agricultores familiares, o cultivo de dendê nas suas terras provoca uma redução de produção de alimentos, característica da agricultura familiar, pondo em xeque a segurança alimentar dessas famílias e em 


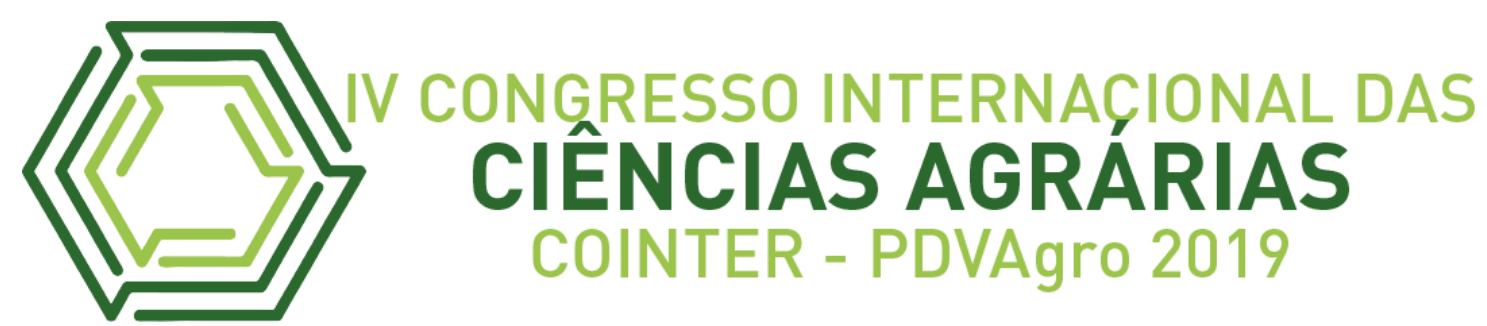

muitos casos, a renda familiar fica limitada exclusivamente a atividade de monocultura de dendê.

Com a implantação de grandes áreas de cultivos de dendê tem-se a redução da biodiversidade na região, diminuindo o número de aves e mamíferos da região e com isso ameaçando a qualidade de vida na comunidade local e a manutenção das condições socioambientais. Além disso, o uso de agrotóxicos na cultura provoca a contaminação dos recursos hídricos superficiais da região, comprometendo o uso da água para determinados fins.

Conclui-se que a atividade agrícola de dendeicultura no Nordeste Paraense é importante e necessária atividade econômica para o estado do Pará e essa atividade provoca impactos socioambientais positivos e negativos, especialmente para a agricultores familiares da região produtora.

\section{REFERÊNCIAS BIBLIOGRÁFICAS}

BASA. A experiência do Banco da Amazônia com projetos integrados de dendê familiar. Revista Contexto Amazônico. Ano 5, n. 22.2012.

Biopalma da Amazônia S/A. Disponível em: < https://www.biopalma.com.br/> Acesso em: 08 de julho de 2019.

BRAZILIO, Marcia; BISTACHIO, N. J.; PERINA, V. de C. S.; NASCIMENTO, D. D. do. Bioenergia em revista: diálogos, v. 2, n. 1, p.27-45, jan./jun. 2012.

BRITO, M. A. Boas Práticas: COMO MINIMIZAR OS IMPACTOS SOBRE A BIODIVERSIDADE AMAZÔNICA - A Experiência da Agropalma. Disponível em:< http://fbds.org.br/fbds/Apresentacoes/10_Biod_Amaz_Agropalma_M_Brito.pdf > Acesso em: 19 jul. 2019.

CRUZ, R. H. R. ; FARIAS, A. . Impactos Socioambientais de Produção de Palma de Dendê na Amazônia Paraense: Uso de Agrotóxicos. Revista Geoamazônia, v. 5, p. 86, 2017.

DENPASA. Considerações sobre os aspectos econômicos de um projeto para uma plantação de dendô. Belém, 1979. iSp.

FURLAN, J. et al. Biodiesel. Porque tem que ser dendê. Belém: EMBRAPA/PALMASA, 2006. 


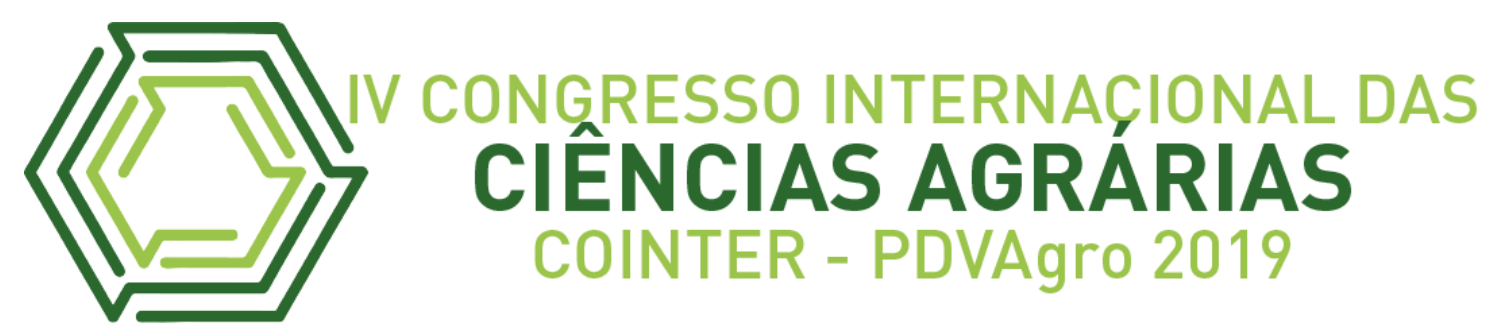

GLASS, V.. O relatório "Expansão do dendê na Amazônia brasileira: elementos para uma análise dos impactos sobre a agricultura familiar no nordeste do Pará" In: Repórter Brasil - Organização de Comunicação e Projetos Sociais. 2013, 15pag.

HAESBAERT, R. O mito da desterritorialização: do "fim dos territórios" à multiterritorialidade. Rio de Janeiro: Bertrand Brasil, 2004.

HOMMA, A. K. O; VIEIRA, I. C. G. Colóquio sobre Dendezeiro: Prioridades de pesquisa econômicas, sociais e ambientais na Amazônia. Amazônia: Ci. \& Desenv., v. 8, n. 15, p.79-90, jul./dez. 2012.

Ministério do Desenvolvimento Agrário - MDA, Relatório Técnico. Brasília: 2005

MÜLLER, A. A. ; ALVES, R. M. . A dendeicultura na Amazônia brasileira.. Documentos , Belém, v. 1, n.1, 1997.

MÜLlER, A. A. Possibilidade de consorciamento com dendezeiro. Trabalho apresentado como palestra no primeiro seminário da Agricultura Familiar com a dIntrodução do Dendê. Moju: 2005.

NAHUM, J. S.; SANTOS, C. B. A dendeicultura na Amazônia paraense. Geousp Espaço e Tempo (Online), v. 20, n. 2, p. 281-294, mês. 2016. ISSN 2179-0892.

NAHUM, J. S.; SANTOS, C. B. dos. Impactos socioambientais da dendeicultura em comunidades tradicionais na Amazônia paraense. Acta Geográfica (UFRR), p. 63-80, 2013.

NAHUM, J. S; BASTOS, C. S. Dendeicultura e descampesinização na Amazônia paraense. In: Campo-território: revista de geografia agrária, v. 9, n. 17, p. 469-485, abr., 2014. Disponível em: <http://www.seer.ufu.br/index.php /campo territorio /issue /view /1113>. Acesso em: 08 jul. 2019.

PANDOLFO, C. A cultura do dendê: possibilidades de seu desenvolvimento na Amazônia. Palestra pro ferida no seminário Governo e iniciativa privada na Amazônia Resultados socio-econô micos. São Paulo, março, 1978.

SANTOS, M. M.; VALOIS, A.C.C.; ROCHA NETO, O. G. Programa Nacional de pesquisa de Dendê na Embrapa: Bases Sólidas para o Desenvolvimento desta Cultura no Brasil. In: $1^{\circ}$ Simpósio do Trópico Úmido, 1984, Belém. Resumos do $1^{\circ}$ Simpósio do Trópico Úmido. Belém: Embrapa CPATU, 1984. p. 251-251.

SILVA, E. M.; NAVEGANTES-ALVES, L. F. . Transformações nos sistemas de produção familiares diante a implantação do cultivo de dendê na Amazônia Oriental. Desenvolvimento e Meio Ambiente (UFPR), v. 40, p. 345-364, 2017. 


\section{CONGRESSO INTERNAÇIONAL DAS CIÊNCIAS AGRARIAS \\ COINTER - PDVAgro 2019}

SIQUEIRA, A. S. O avanço do dendê no nordeste paraense e seus impactos a produção familiar e a projeção para o município de Santo Antônio do Tauá. Ananindeua, Pará, p 4-23. 2018

VEIGA, A. S.; BORGES, P. P. V.; RAMOS, E. J. A.; PINA, A. J. de A. et al. Denpasa - Dendê do Pará S/A. Disponível em: < http://denpasa.com.br/pt-br/ > Acesso em: 08 jul. 2019.

VENTURIERI, A.; MOURÃO, M.; NASCIMENTO, J. de D.; BOARI, A de J.; GOMES, R. A. Áreas prioritárias para a expansão da dendeicultura no estado do Pará: Uma análise do zondendê e a ocorrência do amarelecimento fatal do dendezeiro. eco debate, v. 00, p. 00-00, 2016.

WANDERLEY, M. N. B. O mundo rural como espaço de vida: reflexões sobre a propriedade da terra, agricultura familiar e ruralidade. Porto Alegre: Editora da UFRGS, 2009. 